\title{
Ecological Risks from Contamination of Ukrainian Soils by Persistent Organic Pollutants
}

\author{
Lidiya Moklyachuk ${ }^{1}$, Oksana Drebot ${ }^{1}$, Oleksandr Moklyachuk ${ }^{2, *}$, Tetyana Moklyachuk ${ }^{1}$, \\ Veronika Monarh ${ }^{1}$ \\ ${ }^{1}$ Institute of agroecology and environmental management UAAS, 03143, Kiev, Ukraine \\ ${ }^{2}$ National Technical University of Ukraine "Kyiv Polytechnic Institute" \\ *Corresponding Author: omoklyachuk@gmail.com
}

Copyright (C) 2014 Horizon Research Publishing All rights reserved.

\begin{abstract}
In order to assess the environmental risks of POPs contaminated areas, we construct a mathematical model that describes spreading of environmental pollution by persistent organic pollutants from areas around old chemical storehouses. Absolute and relative ecological risks of this pollution are calculated. We test our model in real conditions along with the well-known CalTOX model.
\end{abstract}

Keywords Obsolete Pesticides, Ecological Risk, Mathematical Model

\section{Introduction}

Production of high-quality agricultural production is possible on clean soil only. In Ukraine, areas around abandoned pesticide storehouses are still the main source of the pesticide soil pollution. These storehouses were used for a long time for storage of large quantities of pesticides. Most of pesticides that were stored in these storehouses are very dangerous. For example, there are 10 pesticides in the list of persistent organic pollutants (POPs) [1]. In USSR times, obsolete pesticides were accumulated in storehouses and scrapyards all around Ukraine. Spread of POPs into environment cause extreme danger for people and nature due to contamination of ground water, drinking water, plants and animal organisms. According to the Ministry of Ecology and Natural Resources of Ukraine, there are over 3000 pesticide storehouses situated on the territory of the country, not taking into account almost 2000 so-called "hot spots" polluted sites of ruined storehouses. In 2010, The Ministry began implementing a major program aimed for hazardous waste disposal in Ukraine. This program is one of the most priority programs of the Ministry. Dangerous pesticides are transported for safe disposal to specialized factories outside of Ukraine due to lack of such factories on the territory of the country [2].

However, disposal of obsolete pesticides does not solve the problem of environmental pollution with pesticides. Due to long-term storage and usage of large quantities of pesticides, areas around pesticide storehouses are polluted with high concentrations of persistent toxic compounds. Pollution from such sources spread over the large distances [1], including nearby agricultural fields. This results the pollution of agricultural production. Usage of this production causes direct threat to the human organism [3].

As we can see, there is an urgent need of cleaning of polluted soils in Ukraine. However, there are large numbers of different methods of soil cleaning that vary in cost, speed and efficiency. To solve the problem of choosing of the cleaning method, we use methods of ecological risk assessment to select the most efficient, environmentally safe and cheap method.

\section{Materials and Methods}

To estimate the risk for the territory with the obsolete pesticide storehouse, we have to know the total mass of POPs situated in the soil of the studied plot. We know that the highest concentration of PS is observed on the area around a storehouse. According to our previous researches, POPs concentration will decrease with the increase of the distance from the storehouse [4]. To determine the relationship between POPs concentration and distance from the storehouse, we use mathematical method of non-linear regression, namely, exponential regression $[5,6,7,8]$. To calculate the total mass of PS knowing relationship between PS concentration and the distance, we use practical aspects of theory of multiple integrals [9, 10, 11], and differential equations $[11,12,13]$.

To characterize the residual amount of pesticides in soil near pesticide warehouses, we studied organochlorine pesticide 4,4'-DDT and its metabolites (2,4-DDT, 4,4'-DDE, 4,4'-DDD). Soil and plant sampling were conducted according to engineering specifications and state standards for Ukraine (ISO 10381, ISO 6498). Soil samples were taken using the method of compass point grid. Selection was conducted along four transects in each direction from a 
warehouse (north, south, east, and west). Six samples were collected on each transect at distances of $1,5,10$ and 15 meters from the warehouse. Soil was stored in paper bags prior to transfer to labeled plastic bags for transport to the laboratory. Soil samples were stored frozen until analysis. Sampled plants were carefully cleaned and separated into roots and shoots for analysis.

Organochlorine pesticides were quantified by gas chromatography $(\mathrm{GC})$ using an electronic-capture detector (ECD) according to accepted engineering specifications and state standards for Ukraine (ISO 10382, ISO 14181). Determination of pesticide concentration in soil took place in the Ecotoxicology department of the Institute of Agroecology and Environmental Economy UAAS.

We estimate the risk of pollution of agricultural lands neighboring obsolete pesticides storehouses on four sites on the steppe territory of Ukraine.

Google Maps software was used for sites area estimation. To process all formula and data calculations we used Wolfram Mathematica 8.

\section{Persistent Pesticides Pollution Risk Models}

Risk itself is the measure of danger and can be described as cumulative factor of possibility of beginning of undesired event and its consequences. Risk is the quantitative characteristics of the complex of all dangers.

Risk management means analysis of the risk situation, development and reasoning of the decision aimed to minimize this risk. The most important principle of risk assessment is taking into account of all existing dangers in the specific case. Total risk from these dangers has to be lover then some "acceptable level".

Risk assessment model consists of four parts. The first part is the characterization of risk and estimation of the danger level. The second part is assessment of the "acceptable level" of the risk. According to the results of the first stage, the level of risk acceptance is assessed. The third part of the model is selection of methods of risk minimization. The fourth and the final part is development of regulatory and normative acts to implement methods, developed in the third part $[14,15,16]$. Risk factors are divided into two major groups: individual risks (caused by risk subject's actions) and situational risk (caused by situation) [17].

Our task is to estimate risk caused by pollution of the POPs storehouse territory, namely, risk caused by independent factors. This risk is situational, and we have to estimate absolute and relative level of this risk. Levels of this risk depend on many factors, such as soil pollution level, soil pollution composition, toxicological properties of pollutants, epidemiological parameters, local soil parameter etc.

We consider two different methods of ecological risk estimation. First one is the CalTOX model, software developed in the University of California [18, 19]. The second method is described in [20] and is the modification of developed in the Institute of Ecohygiene and Toxicology of L.I. Medved (see [21, 22]).

\subsection{The CalTOX model}

CalTOX is an automated risk assessment system developed by California Department of Toxic Substances Control. The system consists of different Excel spreadsheet data sets and scripts and is able to assess the risk of human exposure to different pollutants through environmental media. CalTOX consists of multimedia transport and transformation model, multi-pathway exposure models and a set of models for variability evaluation that use probabilistic approach to process input values in the terms of mean values and coefficients of variation.

CalTOX constructs the distribution of individual lifetime risk attributable to cumulative exposures over the duration ED (years), to a contaminant in soil at an initial concentration. This is done by integrating the soil concentration in time and then summing the dose and effect attributable to this soil concentration over exposure routes, over environmental media, and over exposure pathways.

The main formula of the CalTOX model is:

$$
\begin{aligned}
H(E D)= & C_{S}(0) \times \sum_{(\mathrm{j} \text { routes })} \sum_{(\mathrm{k} \text { media) }} \sum_{(\mathrm{i} \text { exposure })}\left[Q_{j}\left(A D D_{i} j k\right) \times\right. \\
& \left.\times\left(\frac{A D D_{i j k}}{E D \times C_{k}}\right) \times \int_{0}^{E} D \Phi\left[C_{S}(0) \rightarrow C_{k}, t\right] d x\right]
\end{aligned}
$$

In the above expression, $\Phi\left[C_{S}(0) \rightarrow C_{k}, t\right]$ is the dispersion function that converts the contaminant concentration, $C_{S}(0)$, $\mathrm{mg} / \mathrm{kg}$ measured in soil at time zero, into contaminant concentration, $C_{k}$, at a time, $t$, in environmental medium, $k$. $\left(A D D_{i j k} / C_{k}\right)$ is the the average daily potential dose from exposure medium, $i$, by route, $j$, attributable to environmental compartment, $k$, divided by the normalizing concentration $C_{k}$, which is an average concentration over the duration, $E D$. Exposure media factors are summed over the number of exposure media that link potential dose by route, $\mathrm{j}$, to contaminants in compartment, $k . Q_{j}\left(A D D_{i j k}\right)$ is the function that relates the potential dose, $A D D_{i j k}$, by route $j$ to the lifetime probability of detriment per individual within the population [18]. More details on the CalTOX model can be found on the web page of the project http://www.dtsc.ca.gov/AssessingRisk/caltox.cfm and in $[18,19]$.

\subsection{The SitRisk Model}

Method provided in [21, 22] (SitRisk) describes another approach of ecological risk estimation. Modification of this method, provided in [20], gives the possibility of estimation if risk level when pesticides storehouse is present close to the 
analyzed site.

General SitRisk model has the following form:

$$
R=\frac{1}{2 I S C} \sum_{\substack{\text { exposure } \\ \text { media }}}\left[\mathrm{A}_{i}+\mathrm{B}_{i}+D_{i}\right],
$$

where $I s c$ is the soil self-cleaning index, calculated using location parameters, $A_{i}$ - load of $i$-th pollutant with respect to the influence on human, or how the selected pollutant will affect human organism while direct exposure, $B_{i}$ - load of $i$-th pollutant with respect to the maximum permitted concentration level, or how large and how toxic is the contaminated area in terms of risk, $D_{i}$ - load of $i$-th pollutant with respect to the population exposure, or consequences of indirect exposure of human population with goods, produced on polluted area[21].

Initial model allows risk estimation only when pollutants are uniformly distributed across the studied site. Our modification allows using this model when there is a "hot spot", for example, abandoned pesticide storehouse situated on the studied site.

For calculation of $A_{i}$, Direct Pesticide Load of $i$-th pesticide has to be calculated. This value is equal to total mass of the pesticide on the site divided by the area of the site in hectares. If we have uniformly distributed pollution, it is quite a simple task, but, with a pesticide storehouse present on the site, we have to take into account its influence on pollution levels when calculating the Direct Pesitcide Load.

To calculate Direct Pesticide Load, we used differential equations $[11,12,13]$ and non-linear regression $[5,6,7,8]$ to build the model of distribution of pollution depending on the distance from the storehouse:

$$
P_{i}(x)=P s_{i} \times l_{i} \times \operatorname{Exp}\left\{-m_{i} x+1\right\},
$$

where $P_{i}(x)$ is the pollution level if the $i$-th pesticide, $P S_{i}$ - pollution of area around the storehouse by the $i$-th pesticide, $\operatorname{Exp}\left\{-m_{i} x+1\right\}$ - exponential function, $l_{i}, m_{i}$ - regression coefficients. For calculations of coefficients for this formula we used Wolfram Mathematica 8.

To estimate the total mass of the pesticide, we used practical aspects of multiple integrals $[9,10,11]$. We divided area of the storehouse into ring sectors of some width, and enumerated them with respect to the increase of the distance. If we receive $N$ sectors, then the area of the sector number $k$ can be calculated as

$$
S_{k}=\pi \frac{\beta_{k}-\alpha_{k}}{2}\left(r_{k}^{2}-r_{k-1}^{2}\right),
$$

where $\alpha_{k}$ and $\beta_{k}$ are the starting and the ending azimuth angles of the ring sector, $r_{k}$ is the outer radius of the $k$-th sector, and $r_{k-1}$ is the outer radius of the $k-1$-th sector (or the inner radius of the $k$-th sector, which is the same).
Then, total area of the site can be estimated as

$$
S=\sum_{k=1}^{N} S_{k} .
$$

If we divide the territory of the site in that way, we can, given equation (1), calculate the total mass of the $i$-th pesticide of the field. Taking into account soil density $\theta$, total mass of the $i$-th pesticide, according to $[9,10,11]$, can be found as

$$
\begin{array}{r}
M_{i}=\theta \sum_{k=1}^{N} \int_{\alpha_{k}}^{\beta_{k}} \int_{r_{k-1}}^{r_{k}} P_{i}(x) d x= \\
=\theta \sum_{k=1}^{N} \int_{\alpha_{k}}^{\beta_{k}} \int_{r_{k-1}}^{r_{k}} P s_{i} \times l_{i} \times \operatorname{Exp}\left\{-m_{i} x+1\right\} d x= \\
=\theta \sum_{k=1}^{N}\left(\operatorname{Exp}\left\{-m_{i} r_{k-1}\right\}-\operatorname{Exp}\left\{-m_{i} r_{k}\right\}\right)\left(\beta_{k}-\alpha_{k}\right) \frac{P_{S_{i}} l_{i} * \operatorname{Exp}\{1\}}{m_{i}} .
\end{array}
$$

If we divide $M_{i}$ by $S$, we get the $i$-th pesticide's Direct Pesticide Load, and, after that, we can calculate the $A_{i}$ component of the SitRisk model, and, consequently, use this model for risk calculation in the conditions when there is a pesticide storehouse on the site

\section{Screening Analysis and Risk Assessment}

We conducted screening of pesticides in soil on the sites, mentioned above. Screening data is represented in Table 1.

Using the method of compass points grid, we have determined level of pollution on the distance of 1, 5, 10 and 15 meters from each of the storehouse. This data was used for estimation of the further pollution spreading using exponential regression. The results of measurements and estimated pollution levels are represented in Table 2.

To measure the area of the site we used azimuth and distance tools of Google Earth software. In Wolfram Mathematica 8 software environment, we calculated total mass of the each pollutant of each site. The results of these calculations are displayed in Table 3.

Considering the obtained data, we conducted estimations of risk levels for selected sites using both CalTOX and SitRisk models. For control value we used virtual site with uniform pollution at the maximum allowed concentration level.

\subsection{CaITOX risk Estimations}

In Table 4, CalTOX model output for selected sites is presented. Figures 1-5 display dose distribution of pollutant according to the model, and Figure 6 display relative risk of the pollution on selected sited.

On Figures 1-5, distribution of doses can be similar, but doses of pollutants vary. 
Table 1. Results of soil screening for pesticides

\begin{tabular}{|c|c|c|c|}
\hline \multirow{2}{*}{ Location name } & Pollutant & $\begin{array}{c}\text { Concentration, } \mathrm{mg} / \mathrm{kg} \\
\mathrm{mg} / \mathrm{kg}\end{array}$ \\
\hline \multirow{3}{*}{ Site 1 } & $\sum \mathrm{HCH}$ & 12.32 & 0.1 \\
\cline { 2 - 4 } & $\sum \mathrm{DDT}$ & 19.65 & 0.1 \\
\hline \multirow{2}{*}{ Site 2 } & $\sum \mathrm{HCH}$ & - & 0.1 \\
\cline { 2 - 4 } & $\sum \mathrm{DDT}$ & 0.13 & 0.1 \\
\hline \multirow{2}{*}{ Site 3 } & $\sum \mathrm{HCH}$ & - & 0.1 \\
\cline { 2 - 4 } & $\sum \mathrm{DDT}$ & - & 0.69 \\
\hline \multirow{2}{*}{ Site 4 } & $\sum \mathrm{HCH}$ & 58.63 & 0.1 \\
\hline
\end{tabular}

Table 2. Concentration of pesticides in soil on different distances from the storehouse

\begin{tabular}{|c|c|c|c|c|c|c|c|}
\hline Location name & Pesticide & $1 \mathrm{~m}$ & $5 \mathrm{~m}$ & $15 \mathrm{~m}$ & $25 \mathrm{~m}$ & $50 \mathrm{~m}$ & $100 \mathrm{~m}$ \\
\hline \multirow{3}{*}{ Site 1 } & $\sum \mathrm{HCH}$ & 12.32 & 9.7 & 8.73 & 6.45 & 3.89 & 1.41 \\
\cline { 2 - 8 } & $\sum \mathrm{DDT}$ & 13.86 & 8.02 & 2.65 & 1.25 & 0.38 & 0.06 \\
\hline \multirow{3}{*}{ Site 2 } & $\sum \mathrm{HCH}$ & - & - & - & - & - & - \\
\cline { 2 - 8 } & $\sum \mathrm{DDT}$ & 0.13 & 0.06 & 0.01 & - & - & - \\
\hline \multirow{3}{*}{ Site 3 } & $\sum \mathrm{HCH}$ & - & - & - & - & - & - \\
\cline { 2 - 8 } & $\sum \mathrm{DDT}$ & 0.69 & 0.32 & 0.07 & 0.01 & - & - \\
\hline \multirow{3}{*}{ Site 4 } & $\sum \mathrm{HCH}$ & - & - & - & - & - & - \\
\cline { 2 - 8 } & $\sum \mathrm{DDT}$ & 55.01 & 34.51 & 15.38 & 9.26 & 3.47 & 0.53 \\
\hline
\end{tabular}

Table 3. Site parameters

\begin{tabular}{|c|c|c|c|c|}
\hline Location name & Site area, ha & Pesticide & Total pollutant mass, $\mathrm{kg}$ & Direct pollutant load, $\mathrm{kg} / \mathrm{ha}$ \\
\hline \multirow{2}{*}{ Site 1} & \multirow{2}{*}{41.98} & $\sum \mathrm{HCH}$ & 11.392 & 0.271368 \\
\hline & & $\sum \mathrm{DDT}$ & 6.281 & 0.149619 \\
\hline \multirow{2}{*}{ Site 2} & \multirow{2}{*}{89.90} & $\sum \mathrm{HCH}$ & - & - \\
\hline & & $\sum \mathrm{DDT}$ & 0.861 & 0.00958 \\
\hline \multirow{2}{*}{ Site 3} & \multirow{2}{*}{96.93} & $\sum \mathrm{HCH}$ & - & - \\
\hline & & $\sum \mathrm{DDT}$ & 23.73 & 0.2448 \\
\hline \multirow{2}{*}{ Site 4} & \multirow{2}{*}{20.79} & $\sum \mathrm{HCH}$ & - & - \\
\hline & & $\sum \mathrm{DDT}$ & 84.453 & 4.06227 \\
\hline
\end{tabular}


Table 4. CalTOX model output

\begin{tabular}{|c|c|c|c|c|c|}
\hline Location & Pollutant & \multicolumn{2}{|c|}{ Absolute value } & \multicolumn{2}{|c|}{ Total Absolute Value } \\
\hline \multirow{4}{*}{ Site 1} & \multirow{2}{*}{ DDT } & Risk & $6.55501 \mathrm{E}-06$ & Risk & 7.05002E-06 \\
\hline & & Hazard ratio & 0.23348212 & Hazard ratio & 0.347468697 \\
\hline & \multirow{2}{*}{$\mathrm{HCH}$} & Risk & $4.95015 \mathrm{E}-07$ & & \\
\hline & & Hazard ratio & 0.113986576 & & \\
\hline \multirow{4}{*}{ Site 2} & \multirow{2}{*}{ DDT } & Risk & $7.22734 \mathrm{E}-08$ & Risk & 7.22734E-08 \\
\hline & & Hazard ratio & 0.002540104 & Hazard ratio & 0.002540104 \\
\hline & \multirow{2}{*}{$\mathrm{HCH}$} & Risk & - & & \\
\hline & & Hazard ratio & - & & \\
\hline \multirow{4}{*}{ Site 3} & \multirow{2}{*}{ DDT } & Risk & $3.90181 \mathrm{E}-07$ & Risk & $3.90181 \mathrm{E}-07$ \\
\hline & & Hazard ratio & 0.013693763 & Hazard ratio & 0.013693763 \\
\hline & \multirow[t]{2}{*}{$\mathrm{HCH}$} & Risk & - & & \\
\hline & & Hazard ratio & - & & \\
\hline \multirow{4}{*}{ Site 4} & \multirow{2}{*}{ DDT } & Risk & $2.05983 \mathrm{E}-05$ & Risk & $2.05983 \mathrm{E}-05$ \\
\hline & & Hazard ratio & 0.581048126 & Hazard ratio & 0.581048126 \\
\hline & \multirow{2}{*}{$\mathrm{HCH}$} & Risk & - & & \\
\hline & & Hazard ratio & - & & \\
\hline \multirow{4}{*}{ Control } & \multirow{2}{*}{ DDT } & Risk & $4.01798 \mathrm{E}-08$ & Risk & $5.13124 \mathrm{E}-08$ \\
\hline & & Hazard ratio & 0.000925216 & Hazard ratio & 0.002609791 \\
\hline & \multirow{2}{*}{$\mathrm{HCH}$} & Risk & 4.72944E-07 & & \\
\hline & & Hazard ratio & 0.001684575 & & \\
\hline
\end{tabular}

Table 5. SitRisk model output

\begin{tabular}{|c|c|c|c|c|c|c|}
\hline Location name & Pollutant & A0 & B0 & D0 & Dm & Absolute Risk Value \\
\hline \multirow{4}{*}{ Site 1 } & $\sum$ HCH & 28.4936 & 1.99315 & 93.1018 & 0.005 & 203.604 \\
\cline { 2 - 7 } & $\sum$ DDT & 15.71 & 1.72344 & 44.3875 & 0.005 & 101.343 \\
\cline { 2 - 7 } & Total & 44.2036 & 3.71659 & 137.4893 & & 304.947 \\
\hline \multirow{3}{*}{ Site 2 } & $\sum$ HCH & - & - & - & - & - \\
\cline { 2 - 7 } & $\sum$ DDT & 1.0059 & 0.9088 & 1.49864 & 0.005 & 5.5956 \\
\hline \multirow{3}{*}{ Site 3 } & $\sum$ HCH & - & - & - & - & 200.375 \\
\cline { 2 - 7 } & $\sum$ DDT & 25.704 & 2.23759 & 94.287 & 0.005 & - \\
\hline \multirow{2}{*}{ Site 4 } & $\sum$ HCH & - & - & - & - & 4650.505 \\
\cline { 2 - 7 } & $\sum$ DDT & 426.538 & 3.522885 & 2463.354 & 0.005 & - \\
\hline
\end{tabular}




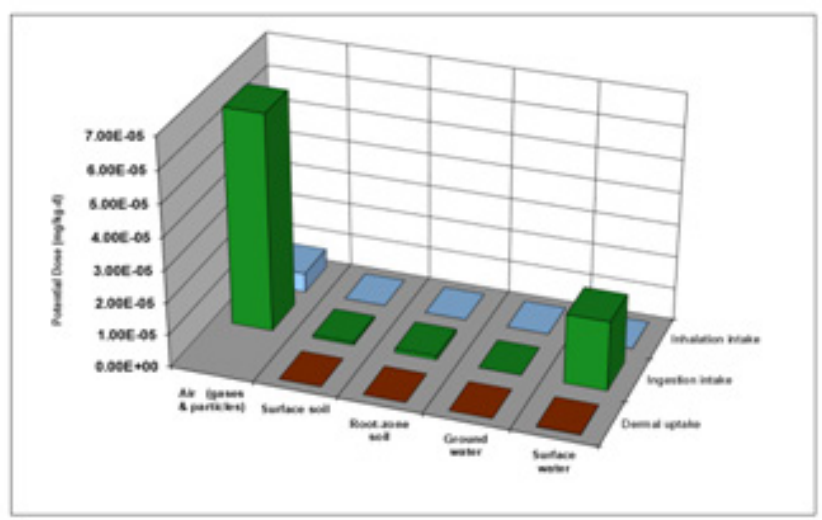

Figure 1. CalTOX model DDT dose distribution on Site 1

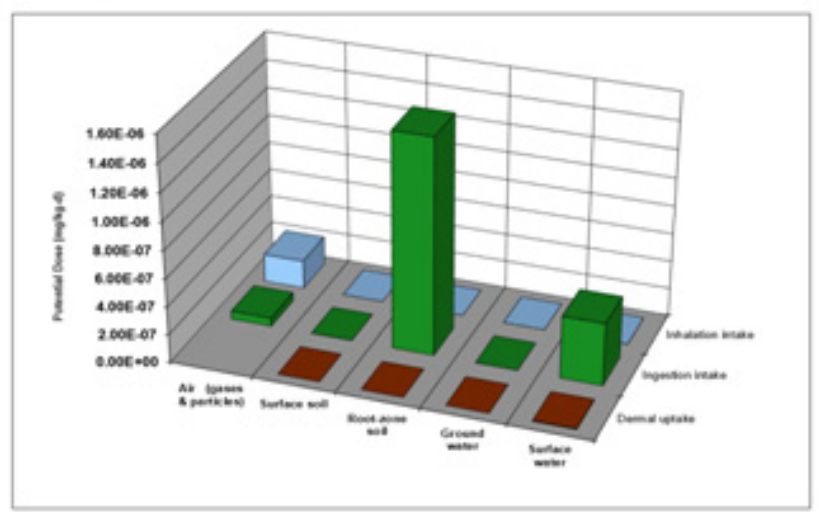

Figure 2. CalTOX model HCH dose distribution on Site 1

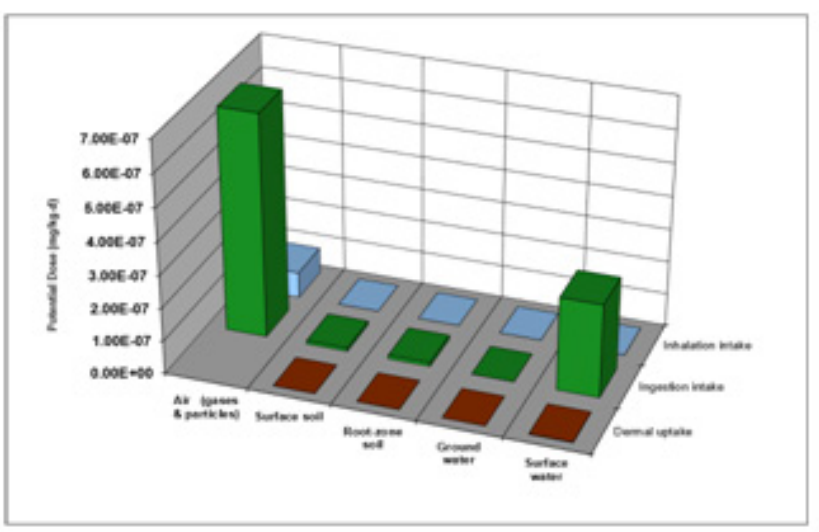

Figure 3. CalTOX model DDT dose distribution Site 2

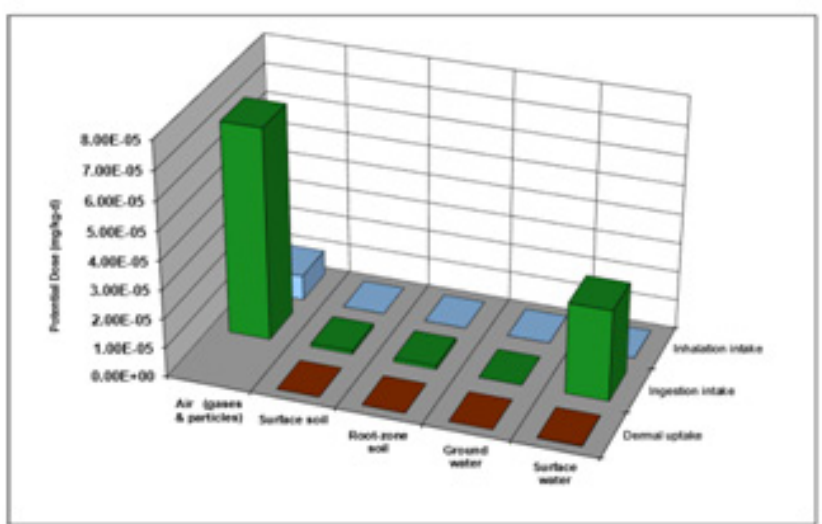

Figure 4. CalTOX model DDT dose distribution on Site 3

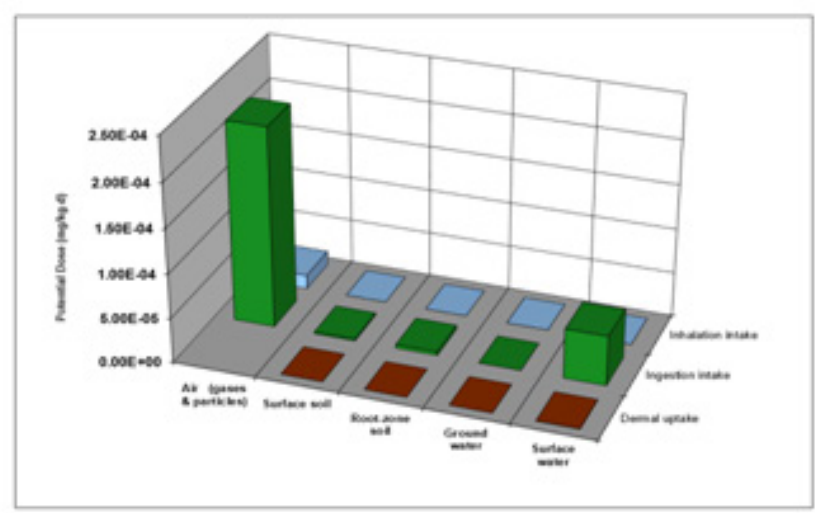

Figure 5. CalTOX model DDT dose distribution on Site 4

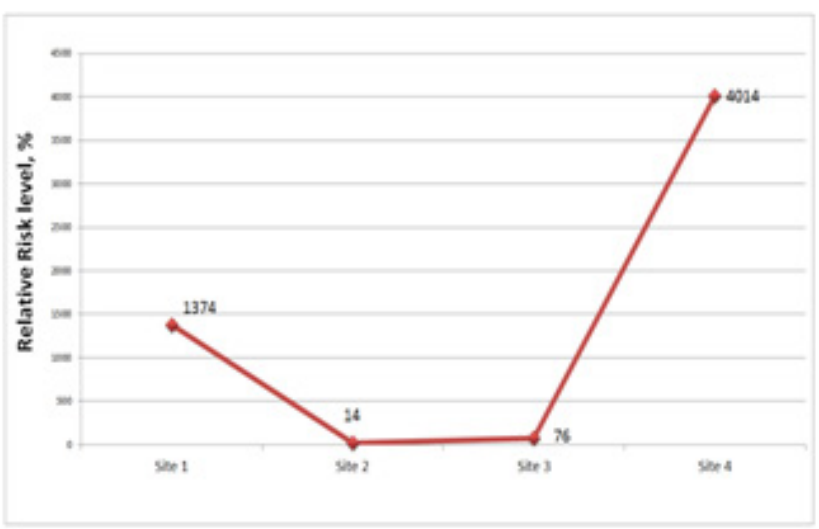

Figure 6. CalTOX model relative risk on selected sites 


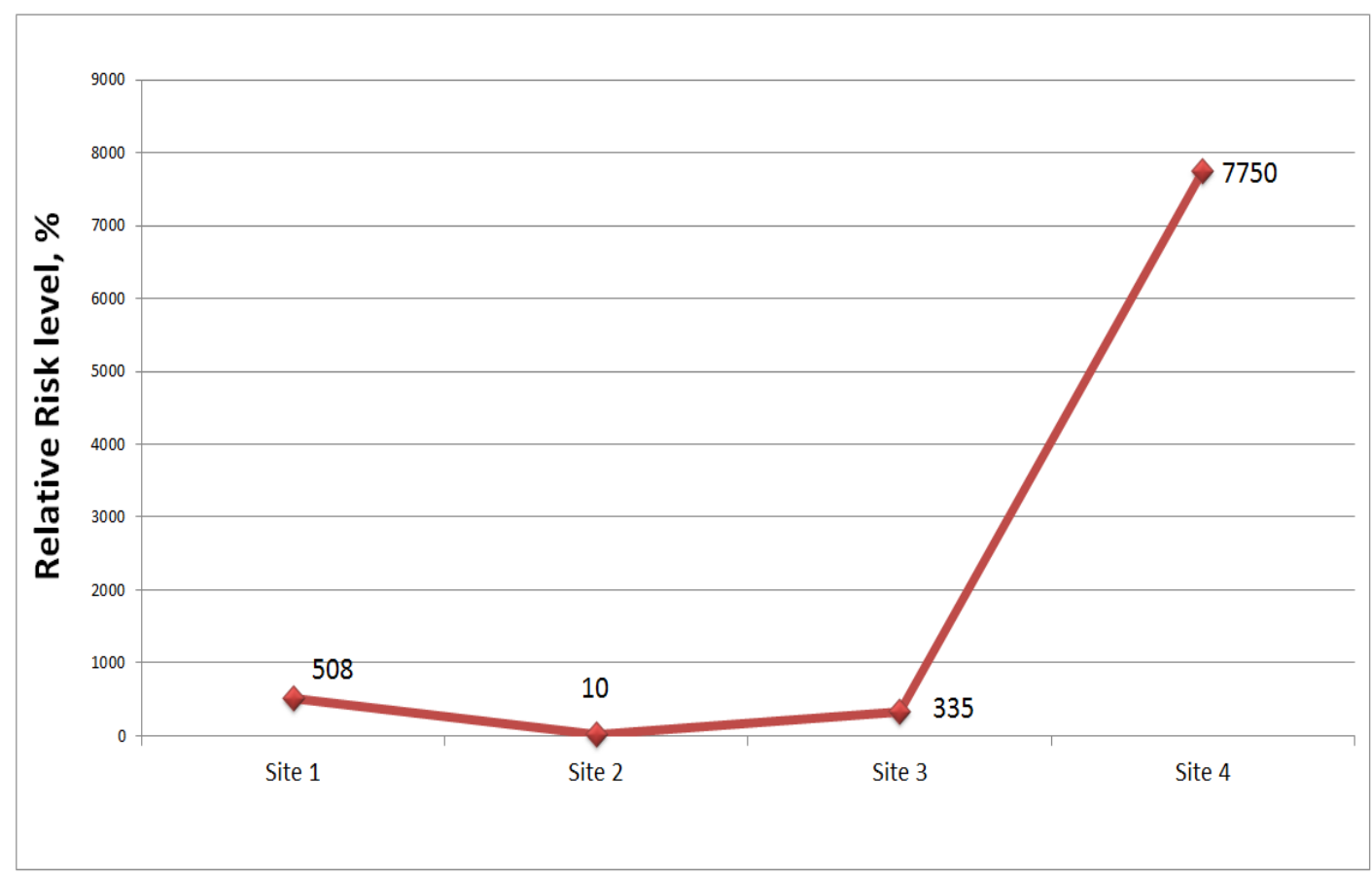

Figure 7. SitRisk model relative risk on selected sites

\subsection{SitRisk Risk Estimations}

Taking into account density of local soil $\left(1.650 \mathrm{t} / \mathrm{m}^{3}\right)$ and the local index of self-cleaning $(I s c=0.61)$ [22], we calculated components of the SitRisk model. The results of the calculations are provided in Table 5; Figure 7 display relative risk of the pollution on selected sites. For control values, we used risk levels provided [22].

\section{Conclusion}

We have studied four sites, polluted with POPs, situated around abandoned pesticide storehouses. For ecological risk estimations, we propose a mathematical model that describes spreading of environmental pollution by persistent organic pollutants from areas around old chemical storehouses. We used the model proposed to accommodate CalTOX and SitRisk models for risk assessment on the sites around abandoned pesticides. Both models give similar results, despite the fact that exact values are different. This confirms the correctness of both approaches. As the result, both models can be used for risk assessment of sites pollution with persistent organic pollutants.

\section{REFERENCES}

[1] Stockholm Convention on Persistent Organic Pollutants, 2001. Online availible: http://www.ipen.org/ipenweb/firstlev el/pops.html

[2] National report on the environmental state in Ukraine in
2011, Ministry of Ecology and Natural Resources of Ukraine, Kiev, LAT-and-K., 2012.

[3] L. Moklyachuk, V. Petryshyna, O. Slobodenyuk, Yu. Zatsarinna. Sustainable strategies of phytoremediation of the sites polluted with obsolete pesticides, Environmental and food safety and security for South-East Europe and Ukraine, Springer-Verlag, New York, LLC, 2012, 81-89.

[4] L. Moklyachuk, I. Gorodiska I., O. Slobodenyuk , V. Petryshyna. Phytoremediation of soil polluted with obsolete pesticides, Application of Phytotechnology for Cleanup of Industrial, Agricultural and Waste water Treatment, Springer-Verlag New York, LLC, 113-124, 2010.

[5] A.M. Yerina. Statistical modeling and estimations, KNEU publishing, Kiev, 2001.

[6] Bethea, R. M.; Duran, B. S.; Boullion, T. L. Statistical Methods for Engineers and Scientists. New York: Marcel Dekker, 1985

[7] Schittkowski, K. Data Fitting in Dynamical Systems. Boston: Kluwer, 2002.

[8] Seber, G. A. F.; Wild, C. J. Nonlinear Regression. New York: John Wiley and Sons, 1989.

[9] I.V. Alekseeva, V.O. Haydey, O.O. Dyhovychnyi, L.B. Fedorova. Differential calculus of functions of several arguments. Defined integrals. Differential equations, NTUU "KPI" publishing, 2011.

[10] Klaus Weltner, Wolfgang J. Weber, Jean Grosjean, Peter Schuster. Mathematics for Physicists and Engineers, Springer-Verlag New York, LLC, 2009.

[11] Richard Courant. Differential and Integral Calculus, Wiley, 2011.

[12] A.M. Samoylenko, M.O. Perestyuk, I.O. Parasyuk. Differential equations, Lybid, Kiev, 2003. 
[13] Martin Braun. Differential Equations and Their Applications: An Introduction to Applied Mathematics, Springer-Verlag New York, LLC, 1993.

[14] A.G. Vetoshkin, G.P. Razzhivina. Civil protection: estimation of industrial safety, Publishing of Penza state architecture-building academy, 2004.

[15] Hallenbeck, William H. Quantitative risk assessment for environmental and occupational health. Chelsea, Mich.: Lewis Publishers, 1986

[16] John M. Lachin. Biostatistical methods: the assessment of relative risks.

[17] K.V. Baldin, S.N. Vorobyov, V.B. Utkin. Management decisions, Trade publishing corporation "Dashkov and K", Moscow, 2006.

[18] CalTOX model description. Availible online: http://www.dtsc.ca.gov/AssessingRisk/upload/techman1-2.p df
[19] M. Matlock, R. Morgan, K. White, R. Avery. An environmental risk assessment using CalTOX, Environmental Exposure and Health, WIT Press, 2005

[20] O.Moklyachuk, T.Moklyachuk, V.Monarh. Ecological risks from pollution of Ukrainian soil by persistent organic pollutants, Proceedings of the international scientific-applied conference "Environmental safety and balanced environmental management in agriculture", DIA publishing, $115-117,2013$

[21] M.G. Prodanchuk, V.I. Veliky, Yu.A. Kuchak. Modeling of methodical approach to toxicology and hygienic estimations and prognosis of situational risk on forming of assortment and sizes of pesticide usage in Ukrainian argiculture, Modern toxicology problems, No.4, 43-46, 2001.

[22] M.G. Prodanchuk, V.I. Veliky, Yu.A. Kuchak. Methodological approach to operative ecohygienic estimation of assortment and sizes of pesticides usage in agriculture of Ukraine, Environment and health, No. 1, 75-78, 2003. 